\title{
The Effect of Temperature on Current-Voltage Characteristics and Dust Charging Characteristics in Low-low temperature ESP
}

\author{
Xuhui Zhang, a , Fuxing Cuil, b, Jiaxin Wang ${ }^{1}$, Ke $\mathrm{Liu}^{1}$, Jinglong $\mathrm{Liu}^{1}$, \\ Haojie Liu ${ }^{1}$, and Guilong Xiong ${ }^{3}$ \\ ${ }^{1}$ State Grid Shandong Electric Power Research Institute, Ji'nan, 250002, China. \\ ${ }^{2}$ School of Resources Environment \& Chemical Engineering, Nanchang University, Nanchang, \\ 330000, China. \\ axuhui901212@163.com, b15098758582@163.com
}

\begin{abstract}
The low-low temperature ESP (Electrostatic precipitator), reducing flue-gas operational temperature to improve dust removal performance, has been used gradually in engineering applications for the capture of fine particles in coal-fired power plant. The effects of temperature on discharge characteristics and dust charging characteristics are examined by using a lab-scale ESP setup. The offline dust resistivity was analyzed by DR dust electrical resistivity test instrument. Results indicate that the corona current decreases and the breakdown voltage increases with the decreasing temperature. The offline dust resistivity increases and then decreases when increasing the temperature with a peak around $130-150^{\circ} \mathrm{C}$. In contrast to ESP operated at $130^{\circ} \mathrm{C}$, the ESP operated at $90^{\circ} \mathrm{C}$ shows a remarkable improvement of dust charging distribution as the decrease of dust resistance and velocity, especially for more residence time of particles in electric field.
\end{abstract}

Keywords: low-low temperature ESP; $\mathrm{PM}_{2.5}$; charging.

\section{Introduction}

The ESP has been used widely for removal dust in coal-fired power plants, the collection efficiency can reach higher than $99 \%$, but exists penetrating windows in the range of $0.1 \mu \mathrm{m}-1 \mu \mathrm{m}[1,2]$, as a result, it is difficult to meet the increasingly strict smoke emission standards. The low-low temperature ESP, reducing flue gas temperature by placing a heat exchanger in front of the electrostatic precipitator, avoids high resistance of fly ash at about $130{ }^{\circ} \mathrm{C}$ and achieves the purpose of efficient dust removal, it is widely used in engineering in China through easy modification[3].

The effects of electric dust precipitator on fly ash can be divided into the processes of dust charging, migration, deposition and removal [4]. The charging amount will affect the particle migration, thus affecting the dust removal efficiency, dust resistance is an important factor in particle charging. A lot of modification of electric precipitators revolve around improving the specific resistance of dust. The relationship between gas temperature and dust resistance has been studied at home and abroad $[2,5]$, relevant literature [6,7] also refer to in-depth analysis of the combined action mechanism of low-low temperature electrostatic precipitator on fly ash and $\mathrm{SO}_{3}$. At present, there are few experimental studies on the effect of temperature on discharge characteristics and dust charging during the application of low-low temperature electrostatic precipitator [8-10].

In this paper, the effects of temperature on discharge characteristics, dust charging characteristics are examined by using a lab-scale low-low temperature ESP setup in order to explore the mechanism of low-low temperature precipitators performance on dust removal.

\section{Test Equipment and Test Methods}

The experimental system of low-low temperature electric precipitator is shown in Fig. 1. Gas circuit can be divided into two parts, one part for main air blower through the heater heating, the other part is the air supply, carrying dust mixed with the main flow, together into the electric dust catcher. In order to guarantee the stability of internal temperature, the setup is equipped with thermal 
insulation layer, which ensure the temperature difference between inlet and outlet within $3{ }^{\circ} \mathrm{C}$. The setup is powered by high-voltage dc power supply, and the air flow after the dust removal is processed by the exhaust filter. There are 3 thermocouples placed at heater outlet and ESP setup inlet and outlet for temperature measurement.

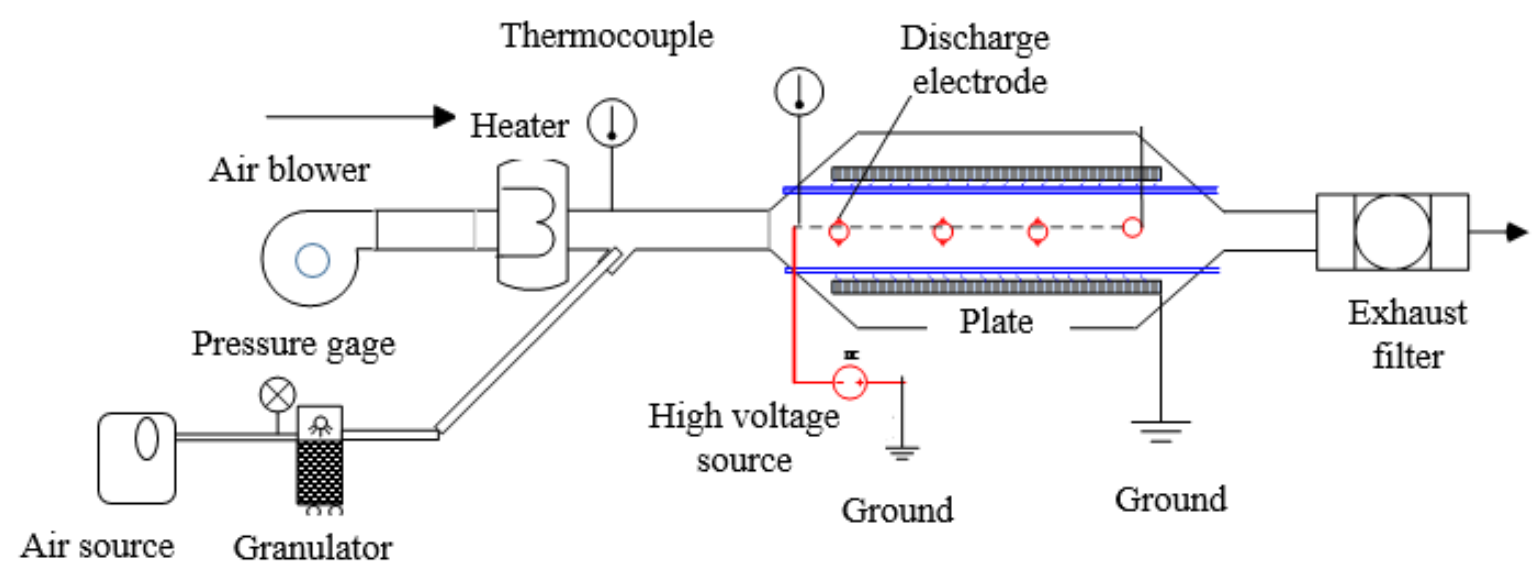

Fig.1 Schematic Diagram of the Lab-Scale ESP Setup System

The size of the electrode plate is $1 \mathrm{~m}^{*} 0.5 \mathrm{~m}$, and the distance between the plates is $0.2 \mathrm{~m}$. Three needle discharge electrodes are arranged at intervals of $0.25 \mathrm{~m}$. The flow rate is designed to be about $0.3 \mathrm{~m} / \mathrm{s}$. After experiments, dust is deposited on the electrode plate, which needs to be cleaned by tapping.

The current limit of dc high voltage power supply is $5 \mathrm{~mA}$, when the current exceeds the limit, high voltage power supply cut off automatically by over-current protection power. When studying the influence of temperature on the discharge characteristics, the voltage corresponding to current of $5 \mathrm{~mA}$ is taken as the breakdown voltage. Before the experiment, the off-line resistance of fly ash was tested in DR dust specific resistance test bench.

The particle charging amount was measured by electrical low pressure impactor (ELPI). In the test process, the concentration of the grading number of particles is obtained first, and then the charge device of ELPI is closed. The resulting current value can be converted into the average charge quantity of each grade of particles according to equation:

$$
q=\frac{I}{N Q e}
$$

Where I is the current value measured at all levels (A); $\mathrm{N}$ is particle number concentration; $\mathrm{Q}$ is the pumping rate.

\section{Results and Discussion}

\subsection{Discharge Characteristic}

The current-voltage curve at the gas temperature of $50{ }^{\circ} \mathrm{C}, 90{ }^{\circ} \mathrm{C}$ and $130{ }^{\circ} \mathrm{C}$ is shown in Fig.2. The results show that the breakdown voltage increases and the corona current decreases with the decrease of flue gas temperature. The gas density increases when temperature decreases, increasing charged particle collision rate with neutral gas molecules and then reducing ion migration rate effectively. The space charge density near the corona pole increases at constant voltage at lower temperature, when the voltage must be near corona polar space charge density increases, this is why the breakdown voltage increases.

The increase of breakdown voltage makes the ESP working at a higher voltage, which increases the field strength dust charging, especially for high resistance dust and $\mathrm{PM}_{2.5}$, it is of great significance to improve the overall efficiency of dust collection [11]. Comparing the current-voltage curve, we can see that the breakdown voltage and corona current change faster as the temperature reducing. 


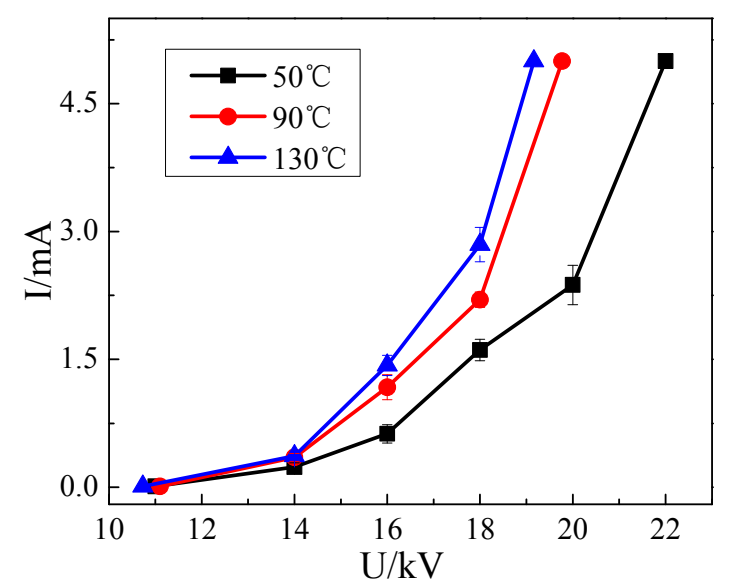

Fig.2 Current-Voltage Curves at Different Temperature

In the experiment, the discharge characteristic under the condition of different dust concentration is studied, as shown in Fig.3. It can be seen from the figure that the dust concentration will have a significant impact on the discharge characteristics, and the increase of dust concentration will lead to the decrease of corona current and the increase of breakdown voltage. It can be explained with the relationship between corona current and dust, gas ion. Corona current is generated from the movement of gas ion and charged particles to plate, but the migration velocity of charged particles is slow because of its high quality and volume compared with gas ion, so the gas ions play a major role in corona current formation. The increase of dust concentration increases in the number of charged particles while decreases gas ion relatively, thus cause corona current decreases.

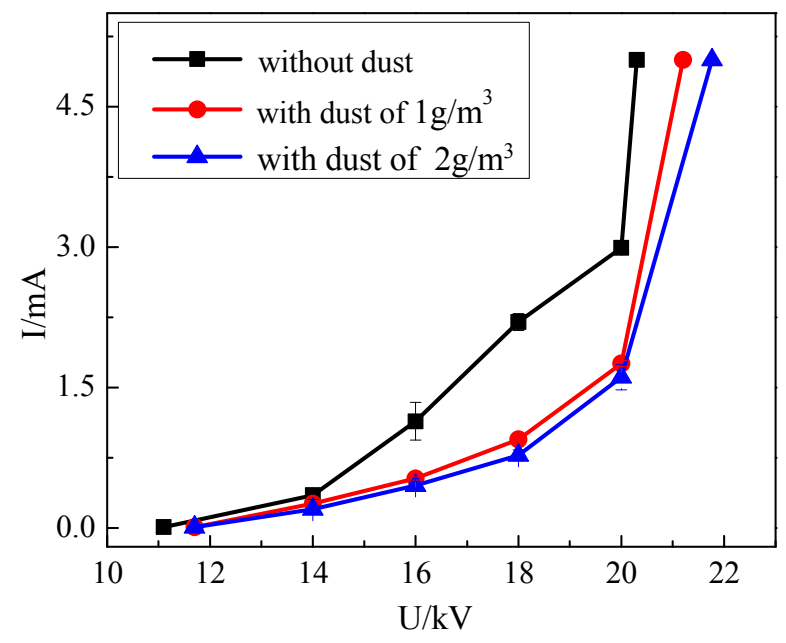

Fig.3 Discharge Characteristic at Different Dust Concentration

\subsection{Offline Dust Resistivity}

The dust off-line resistance analysis was carried out in the experiment, as shown in Fig. 4. Dust resistivity increases and then decreases with the increase of temperature, and reach the maximum at the temperature of $150^{\circ} \mathrm{C}$. Conventional ESP operates at the temperature of about $130{ }^{\circ} \mathrm{C}$, which is in the high dust resistivity larger area. 


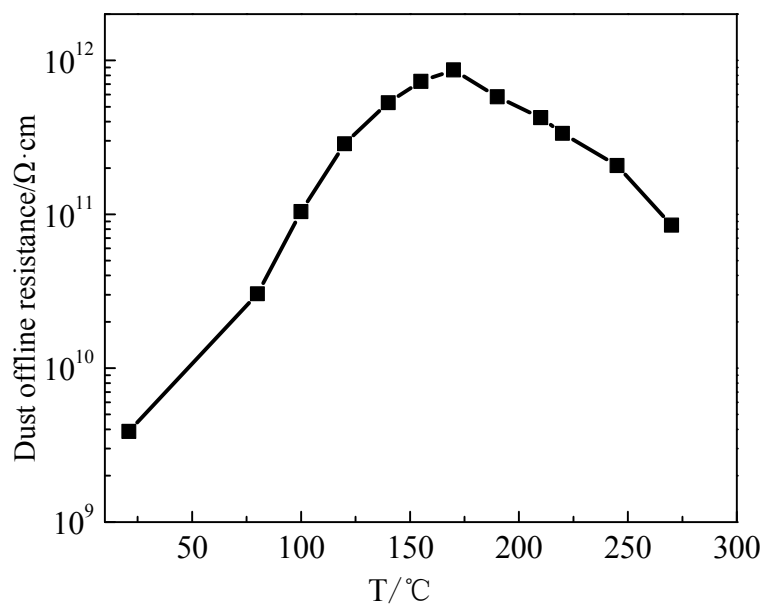

Fig.4 The Relationship between Dust Offline Resistance and Temperature

Dust resistance is an important factor affecting the efficiency of ESP. The dust is easy to remove when the resistivity at the range of $104 \sim 5 \times 1010 \Omega \cdot \mathrm{cm}$, while the removal becomes difficult with higher dust resistance, and there will be a phenomenon of back corona, bring down the dust removal efficiency.

\subsection{Dust Charging Characteristic}

Figure 5 shows the particle average charging amount at the temperature of $90{ }^{\circ} \mathrm{C}$ and $130{ }^{\circ} \mathrm{C}$. In the figure, 1 and 2 indicates that the measuring point is behind the first electrode and the third electrode of the experimental table respectively. After the third discharge electrode, the difference of particle average charging amount between $90{ }^{\circ} \mathrm{C}$ and $130{ }^{\circ} \mathrm{C}$ becomes more apparent, due to longer residence time.

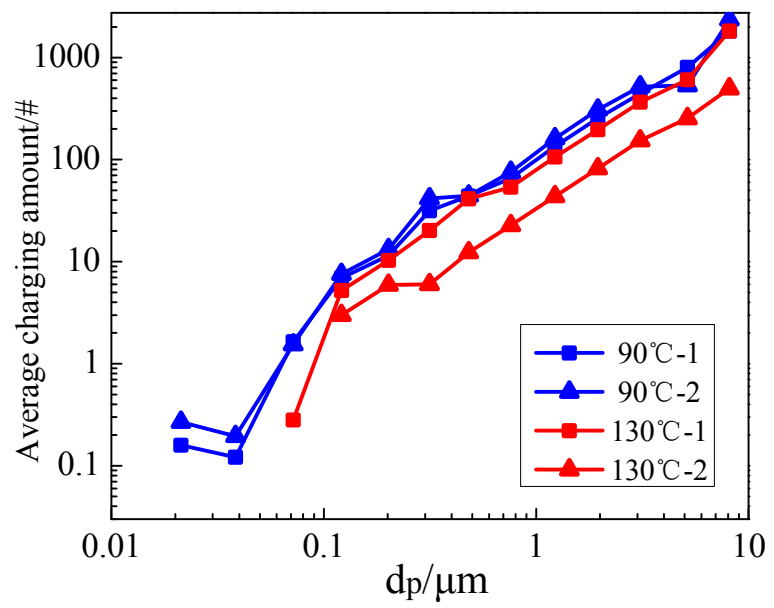

Fig.5 Particle Charging Distribution at the Discharge Voltage of $18 \mathrm{kV}$

Compared with the temperature of $130{ }^{\circ} \mathrm{C}$, the particles average charging amount at $90{ }^{\circ} \mathrm{C}$ significantly increased. The particle charging amount has an important role in the removal of particle. The particle with diameter less than $0.1 \mu \mathrm{m}$ is loaded less than 1 electric charge on average, suggesting that some particles escape without being charged. Meanwhile, the particle charging distributions under different temperatures testify the improvement of charging characteristic with lower temperature. This is benefited from the decrease of dust resistivity. The increase of average charging amount promote the removal of particle. The effect of reducing temperature on particle average charging coincides with that on the removal efficiency and dust resistivity. 


\section{Conclusion}

The effects of temperature on discharge characteristics, and dust charging characteristics are examined by using a lab-scale low-low temperature ESP setup. We find the corona current decreases and the breakdown voltage increases with the decreasing temperature. The offline dust resistivity increases and then decreases when increasing the temperature with a peak around $130-150^{\circ} \mathrm{C}$. In contrast to ESP operated at $130^{\circ} \mathrm{C}$, the ESP operated at $90^{\circ} \mathrm{C}$ shows a remarkable improvement of dust charging distribution, especially for more residence time of particles in electric field.

\section{References}

[1]. Yao Q, Li SQ, Xu HW, et al. Studies on formation and control of combustion particulate matter in China: a review. [J].ENERGY, 2009, 34: 1296-1309.

[2]. Jin X, Research on the Capture Technology of Fine Particles in Electrostatic Precipitator [D]. Tsinghua University, 2013.

[3]. Zhang X.H. Studies on Synergetic Removal of Fine Particulates and SO3 by an Extra Cold-side Electrostatic Precipitator [D]. Tsinghua University, 2015.

[4]. McLean K J. Electrostatic precipitators [J]. Physical Science, Measurement and Instrumentation, Management and Education-Reviews, IEE Proceedings A, 1988, 135(6): 347-361.

[5]. Bäck A. Enhancing ESP Efficiency for High Resistivity Fly Ash by Reducing the Flue Gas Temperature [M]. Electrostatic Precipitation. Springer Berlin Heidelberg, 2009: 406-411.

[6]. Guo B Y, Yu A B, Guo J. Numerical modeling of electrostatic precipitation: Effect of Gas temperature[J]. Journal of Aerosol Science, 2014, 77: 102-115.

[7]. Xiong G.L, LI S.Q, Chen S, et al. Development of Advanced Electrostatic Precipitation Technologies for Reducing $\mathrm{PM}_{2.5}$ Emissions From Coal-fired Power Plants [J]. Proceedings of the CSEE, 2015, 35(09):2217-2223.

[8]. Noda N, Makino H. Influence of operating temperature on performance of electrostatic precipitator for pulverized coal combustion boiler [J]. Advanced Powder Technology, 2010, 21(4): 495-499.

[9]. Bickelhaupt R E, Sparks L E. Predicting fly ash resistivity — an evaluation [J]. Environment International, 1981, 6(1): 211-218.

[10]. Fujishima H, Tsuchiya S. Colder Side ESP of Advanced Flue Gas Treatment System for Coal Fired Boiler[C]//7th International Conference on Electrostatic Precipitation, Kyongju, Korea. 1998: 542-549.

[11]. Hinds W C. Aerosol technology: properties, behavior, and measurement of airborne particles [J]. New York, Wiley-Interscience, 1982. 